\title{
Is student procrastination related to controlling teacher behaviour?
}

Valenzuela, Rafael; Codina, Nuria; Pestana, Jose Vicente; and González-Conde, Joan Department of Social Psychology and Quantitative Psychology, University of Barcelona, Spain

\begin{abstract}
Even motivated students procrastinate, because procrastination is triggered by a volitional (rather than by a motivational) problem. However, many factors, such as learning context, teacher interpersonal style, and also type of motivation may influence the occurrence of procrastination. The aim of the present study was to assess the relations between first-year university students' procrastination and controlling teacher behaviour. Four types of controlling teacher behaviour and three distinct measures of procrastination were evaluated and their correlations assessed. Findings revealed small but significant associations between (a) conditional use of rewards and decisional procrastination, and between (b) excessive personal control and task-avoiding procrastination. Results suggest that controlling teacher behaviour can negatively influence students' learning experiences. By using conditional rewards too often, teachers may deffer their students' autonomous decision processes to engage in academic learning. And teachers trying to exercise excessive personal control may favour their students' perceptions of external regulation, limiting their possibilities of developing intrinsic motivation and autonomous self-regulated learning. Both resulting conditions could make it more likely for students to procrastinate academic learning, by engaging in alternative activities.
\end{abstract}

Keywords: Student procrastination; decisional procrastination; controlling teacher behaviour; conditional use of reward. 


\section{Introduction}

Procrastination has been defined as repeated failure to perform actions necessary to reach one's goals (Lay, 1986) and as a voluntary delay in an intended action course, even knowing that this delay will probably have negative impacts one's own interests (Steel, 2007). All people procrastinate sometimes or punctually (and may not score high in procrastination questionnaires), but some do it regularly and in various situations, thus, being called procrastinators (Dewitte \& Schouwenburg, 2002).

Education and academic success (starting as early as in primary school) is an important aspect of a person's upbringing that can have notorious effects on many components of their life success (Dewitte \& Lens, 2000). But, it has been reported that, as much as around four out of five college students engage in procrastination, and that approximately 50\% do it consistently, suffering at least some negative consequences (Steel, 2007). Some studies have even reported that one out of three students could be considered a severe general procrastinator (Day et al., 2000).

Students who procrastinate tend to underperform their non-procrastinating peers, even under circumstances of similar motivation and skill, suggesting that this lower performance may be explained by volitional causes, rather than motivational or skill-based causes (Dewitte \& Lens, 2000). For example, procrastinators may lack the capacity of transforming their own intentions into action (Lay, 1986), sometimes because they are not able to construct an adequate mental representation of the targeted activity (Dewitte \& Lens, 2000).

It has been argued that early development of motivation towards their studies can help children to overcome various difficulties arising in learning processes (Katz et al. 2011), but the relations between the promotion of specific motivational aspects and diverse types of academic procrastination have not been evaluated thoroughly enough (Katz, et al., 2014).

Systematic efforts to establish links between motivation, performance and wellbeing have come from Self-Determination Theory (Deci \& Ryan, 2000), consistently arguing that context (family, school, teachers, peers, learning setting or socio-cultural contexts) may have multiple and important influences on motivation (Deci, 1971, 1975; Deci \& Ryan, 2008). Specifically, SDT suggests that teachers can have two distinct interpersonal styles when approaching their students' learning processes: they can be either autonomy supportive or controlling (Ryan \& Deci, 2000). Consequently, various studies have advocated for autonomy support as a guiding principle in pedagogy, because it has been found to enhance quality motivation, interest and succesful learning, more than control does (Deci \& Ryan, 1987). In this regard, much consideration has been given to autonomy support, but less attention has been oriented towards analysing the influence of controlling 
behaviours, for example, on psychological experiences of athletes (Castillo et al. 2014) or students.

The present study aimed at contributing to fill in the research gap regarding the relations between various types of motivations (or motivation sources, such as controlling teacher behaviour) and student procrastination. Particularly, it was assessed if three distinct measures of student procrastination were associated with four aspects of controlling teacher behaviour.

\section{Method}

Participants of the present study were 108 first-year university students of the social sciences, 24 were males and 84 females, their ages ranged between 17 and 23 years-old ( $M$ $=18.05, S D=0.86)$. During a regular class session, researchers presented students with questionnaires assessing procrastination and controlling teacher behaviours. Instrument of the present research was a self-report questionnaire, which included three procrastination scales, validated for Spanish adult population and reported by Díaz-Morales et al., (2006): the General Procrastination (GP) Scale (Lay, 1986), which is a one-dimensional 20-item measure that assesses a global tendency towards procrastinating across different situations and has been related to personality traits such as low self control or rebelliousness (DíazMorales et al., 2006); the 5-item Decisional Procrastination (DP) Questionnaire (Mann, 1982, as cited in Díaz-Morales et al., 2006), which evaluates the delay in making decisions that are bound to a specific time frame and in which high scores indicate a tendency towards laying off decision-making processes by doing other things; and the third procrastination scale used was the 15-item Adult Inventory of Procrastination (AIP), which has been related to a general tendency toward avoiding tasks, failing to meet deadlines or not getting things done (McCown \& Johnson, 1989, as cited in Díaz-Morales et al., 2006). Lastly, the instrument included the Controlling Teacher Behaviours Scale (CTBS), derived by the authors from the Controlling Coach Behaviors Scale (Bartholomew et al., 2010, as cited in Castillo et al. 2014). This 15-item measure draws from an SDT-framework to evaluate coached athletes'/students' perceptions of their coaches'/teachers' controlling interpersonal styles, scored on four main aspects: (1) controlling use of rewards (CUR), which refers to the use of tangible and verbal rewards as an incentive for engaging with and completing a task or for reaching certain performance standards (Deci, Koestner, \& Ryan, 1999, as cited in Castillo et al. 2014); (2) negative conditional regard (NCR), which refers to the withholding of love, attention, and affection by those in a position of authority when desired attributes or behaviours are not displayed by their subordinates (Assor, Roth, \& Deci, 2004, as cited in Castillo et al. 2014); (3) intimidation (INT), which refers to the use of strategies to control behaviours in order to humiliate and belittle, such as verbal abuse 
and threats, yelling, and the threat or use of physical punishment (Bartholomew et al., 2010, as cited in Castillo et al. 2014); and, lastly, (4) excessive personal control (EPC); which refers to the use of intrusive behaviours that attempt to interfere with aspects of the athletes' lives that are not directly associated with their sport participation (Bartholomew et al., 2010, as cited in Castillo et al. 2014). Independently of the fact that procrastination items were phrased in first person ("I do", "I am") and controlling teacher behaviour items in third person ("my teachers do", "I have teachers that are"), participants had to rate all items on a 5-point Likert scale, ranging from $1=$ "not at all like me" to $5=$ "very much like me".

The intention was to describe students' perceptions of controlling teacher behaviour (on four different aspects) and assess if these were related to three distinct measures of student procrastination, utilising correlation analyses performed by means of SPSS 23 statistical analysis software package.

\section{Findings}

As Table 1 shows, procrastination among participants received moderate scores, around and below the neutral 3-point mark ( 3 = "sometimes like me, other times not"), suggesting sporadic procrastination. It is noteworthy that general procrastination (GP) received the highest score of the three procrastination scales, but at the same time, with the lowest standard deviation, suggesting that it is regular, among first-year university students, to procrastinate sporadically, when it comes to general situations. Decisional Procrastination (DP) and the measure linked to task avoidance (Adult Inventory of Procrastination - AIP) also received moderate scores, however, their standard deviations were bigger, suggesting that students reported more intersubject variations on these two procrastination scales.

Regarding correlational aspects, general procrastination (GP) was not associated with any of the four measures of controlling teacher behaviour, indicating that this type of procrastination is prevalent among first-year university students, but independent of their teachers' controlling (or alternatively, of their teachers' autonomy-supportive) behaviour.

Furthermore, findings revealed significant associations between (a) conditional use of rewards (CUR) and procrastination (DP); and between (b) excessive personal control (EPC) and high scores on the Adult Inventory of Procrastination (AIP) related to task avoidance, indicating that teaching style was associated with procrastination linked to autonomously deciding to study/learn; and procrastination linked to avoiding getting tasks done. 
Valenzuela, R.; Codina, N.; Pestana, J.V.; González-Conde, J.

Table 1. Descriptives and correlations between three procrastination scales and four controlling teacher behaviours among $(N=108)$ first-year university students.

\begin{tabular}{lcccccccc}
\hline & $M$ & $S D$ & GP & DP & AIP & CUR & NCR & INT \\
\hline GP & 2,70 & 0,49 & & & & & \\
DP & 2,49 & 0,85 & $.42^{* *}$ & & & & \\
AIP & 2,35 & 0,67 & $.70^{* *}$ & $.32^{* *}$ & & & \\
CUR & 1,65 & 0,57 & .11 & $.22^{*}$ & .13 & & \\
NCR & 1,89 & 0,64 & .08 & .07 & .12 & $.36^{* *}$ & \\
INT & 1,30 & 0,34 & .06 & .09 & .11 & $.34^{* *}$ & $.41^{* *}$ & $.33^{* *}$ \\
EPC & 1,44 & 0,46 & .13 & -.03 & $.19^{*}$ & $.33^{* *}$ & .18 \\
\hline
\end{tabular}

Note. $N=108 . * p<.05 ; * * p<.01$. General Procrastination (GP); Decisional Procrastination (DP); Adult Inventory of Procrastination (AIP); Conditional Use of Rewards (CUR); Negative Conditional Regard (NCR); Use of Intimidation (INT); Excessive Personal Control (EPC).

\section{Concluding Remarks}

Academic success is an important part of life success (Dewitte \& Lens, 2000), but procrastination can affect it negatively and is very prevalent among students (Steel, 2007). In this respect, it is clear that motivation can help a person overcome difficulties that arise in any practice, but it is rather unclear in which ways the facilitation of diverse types of study motivation can influence a person's procrastination (Katz, et al., 2014)

Results point in the direction that controlling teacher behaviour might negatively influence students' psychological experiences in learning. Teachers who constantly use conditional rewards may interfere with their students' autonomous decision processes regarding studying. It is possible that this interference may stem from the fact that this kind of teacher behaviour may draw attention to specific tasks (considered important by the teacher), but may at the same time overlook volitional aspects, critical for ongoing engagement and maintanence of high autonomous motivation and self-regulation in learning. With high probability it would be more useful for teachers to give their students recognition when they autonomously study or learn, in this way modelling their autonomous motivation and self-regulation, by drawing attention to (and encouraging), not only the succesful completion of a task, but more importantly the personal disposition that lead the students to get autonomously motivated to learn in a self-regulated manner. 
Furthermore, excessive personal control may favour students' perceptions of external regulations, decreasing intrinsic motivation and autonomous self-regulated learning, thus, making it more likely for them to engage in alternative activities, procrastinating important academic learning. Teachers may benefit from observing the positive effects of autonomous self-regulated learning on their students' motivation and performance. Taking these positive effects into consideration, teachers should find it easier to refrain from trying to exercise excessive personal control, knowing that controlling teacher behaviour tends to negatively affect both student motivation and performance, whereas autonomy-supportive teacher behaviour tends to foster autonomous motivation and self-regulated learning.

Both, the negative effect of conditional use of rewards on students' decisions to study, and the negative effect of excessive personal control on students' academic task completion, signal that teachers' interpersonal teaching styles can interfere with critical volitional processes in which students have to conduct themselves through their learning experiences on their own.

Nowadays, students have access to virtually every piece of information there is; however, the autonomy with which they use new technologies to access, gather and organize information and knowledge should not be put in jeopardy by their teachers' interpersonal styles: if teachers realise that their students will have more chances of developing autonomous motivation and self-regulated learning insofar they foster their interests and their self-perceptions as curious students who autonomously search for new knowledge, they will be putting them in the best of conditions to cope with the standards of society in the information era. Teachers who do not refrain from controlling behaviours may trigger student experiences, which do not lead to better motivation or performance, but rather to interpreting teachers' inputs as external regulations, thus, reacting by focusing their attention on alternative activities, procrastinating academic learning.

\section{References}

Assor, A., Roth, G., \& Deci, E.L. (2004). The emotional costs of parents' conditional regard: A self-determination theory analysis. Journal of Personality, 72, 47-88.

Bartholomew, K.J., Ntoumanis, N., \& Thøgersen-Ntoumani, C. (2010). The controlling interpersonal style in a coaching context: Development and initial validation of a psychometric scale. Journal of Sport \& Exercise Psychology, 31, 193-216.

Castillo, I., Tomás, I., Ntoumanis, N., Bartholomew, K., Duda, J. L., and Balaguer, I. (2014). Psychometric properties of the Spanish version of the Controlling Coach Behaviors Scale in the sport context. Psicothema, 26(3), 409-414. doi: 10.7334/psicothema2014.76 
Day, V., Mensink, D., \& O’Sullivan, M. (2000). Patterns of academic procrastination. Journal of College Reading and Learning, 30, 120-134

Dewitte, S. \& Lens, W. (2000). Exploring volitional problems in academic procrastinators. International Journal of Educational Research, 33: 733-750.

Deci, E. L., \& Ryan, R. M. (2000). The "What" and "Why" of Goal Pursuits: Human Needs and the Self-Determination of Behavior. Psychological Inquiry, 11, 227-268. doi:10.1207/S15327965PLI1104_01

Deci, E. L. (1971). Effects of Externally Mediated Rewards on Intrinsic Motivation. Journal of Personality and Social Psychology, 18, 105-115. doi:10.1037/h0030644

Deci, E. L. (1975). Intrinsic motivation. New York, NY: Plenum.

Deci, E.L., Koestner, R., \& Ryan, R.M. (1999). A meta-analytic review of experiments examining the effects of extrinsic rewards on intrinsic motivation. Psychological Bulletin, $125,627-668$.

Deci, E. L., \& Ryan, R. M. (2008). Facilitating optimal motivation and psychological wellbeing across life's domains. Canadian Psychology, 49, 14-23. doi:10.1037/07085591.49.1.14

Deci, E. \& Ryan, R. M. (1987). The support of autonomy and the control of behavior. Journal of Personality and Social Psychology, 53, 1024-1037. doi:10.1037/00223514.53.6.1024

Dewitte, S. \& Schouwenburg, H. C. (2002). Procrastination, Temptations, and Incentives: The Struggle between the Present and the Future in Procrastinators and the Punctual. European Journal of Personality, 16: 469-489. DOI: 10.1002/per.461

Díaz-Morales, J. F., Ferrari, J. R., Díaz, K. i Argumedo, D. (2006). Factorial structure of three procrastination scales with Spanish adult population. European Journal of Psychological Assessment, 22(2), 132-137.

Katz, I., Eilot, K., \& Nevo, N. (2014). "I'll do it later": Type of motivation, self-efficacy and homework procrastination. Motivation and Emotion, 38, 111-119. DOI 10.1007/s11031-013-9366-1

Katz, I., Kaplan, A., \& Buzukashvili, T. (2011). The role of parents' motivation in students' autonomous motivation for doing homework. Learning and Individual Differences, 21, 376-386. doi:10.1016/j.lindif.2011.04.001

Lay, C. (1986). At last, my research article on procrastination. Journal of Research in Personality, 20: 474-495. 
Mann, L. (1982). Decision making questionnaire I and II. Unpublished scales. Flinders University of South Australia, Bedford Park, South Australia.

McCown, W. \& Johnson, J. (1989). Differential arousal grandients in chronic procrastination. Paper presented at the American Psychological Society, Alexandria, VA.

Ryan, R. M. \& Deci, E. L. (2000). Self-Determination Theory and the Facilitation of Intrinsic Motivation, Social Development, and Well-Being. American Psychologist, 55, 6878. DOI: 10.1037110003-066X.55.1.68

Steel, P. (2007). The Nature of Procrastination: A Meta-analytic and theoretical review of quintessential Self-Regulatory failure. Psychological Bulletin, 133(1), 65-94. 